\title{
Recent Trend of Regenerative Energy Utilization in Traction Power Supply System in Japan
}

\author{
Hitoshi Hayashiya ${ }^{1}$ (D)
}

Received: 15 April 2017/Revised: 24 September 2017/ Accepted: 25 October 2017/Published online: 13 November 2017

(c) The Author(s) 2017. This article is an open access publication

\begin{abstract}
In 2006, the first Lithium-ion battery in Japan was installed in traction power supply system by the West Japan Railway Company and now more than 20 energy storage systems have already been installed in traction power supply system in Japan. In this article, the recent Japanese trends of regenerative energy utilization are summarized not only in DC railway but also in AC railway. We, East Japan Railway Company, have installed three energy storage systems for DC railway and one railway static power conditioner (RPC), not energy storage system, for AC railway for regenerative energy utilization. The effects of these systems are also shown quantitatively in this paper.
\end{abstract}

Keywords Regenerative energy · Electric railway - DC railway $\cdot$ AC traction power supply $\cdot$ Energy storage system - Railway static power converter $\cdot$ Regenerative inverter

\section{Introduction}

Railway transportation is recognized as one of the most ecofriendly transportation modes. For example, $\mathrm{CO}_{2}$ emissions per passenger per kilometer by mode of transportation in Japan are shown in Fig. 1 which was reported by the Japanese Ministry of Land, Infrastructure, Transport and

Hitoshi Hayashiya

hayashiya@jreast.co.jp

1 Tokyo Branch, East Japan Railway Company, 2-20-68, Higashi-Tabata, Kita-Ku, Tokyo 114-8550, Japan

Editor: Dr. Xuesong Zhou
Tourism. As shown in this figure, $\mathrm{CO}_{2}$ emission from railway transportation in carrying one passenger was one-fifth of the amount emitted from airplane and one-seventh of the amount emitted from car in 2013 [1]. The total annual electric energy consumption in railway transportation was, however, 17.7 TW in 2013, and it corresponded to about $1.9 \%$ of total electric energy supply in Japan [2]. It was not a small value, and a lot of railway companies are making efforts to reduce their energy consumptions as small as possible to contribute to solving global warming problem. Such efforts are also important to accomplish our national target to reduce $\mathrm{CO}_{2}$ emission about $26 \%$ of 2013 by 2030 which is mentioned in "Submission of Japan's Intended Nationally Determined Contribution" in UNFCCC COP21 (the United Nations Framework Convention on Climate Change, the Conference of the Parties), Paris [3].

Figure 2 shows the changes in energy consumption in East Japan Railway Company. As shown in this figure, the energy consumption in 2014 was about $10 \%$ smaller than that in 1990. Reduction of energy consumption is eminent in traction power supply for conventional railway, more than $20 \%$ of that in 1990 , by virtue of introduction of energy-saving trains with light bodies, regenerative brakes and VVVF inverters. For station power supply, on the other hand, introductions of LED lightings and high-efficiency air conditioners contributed to the reduction of energy consumption at railway station. For example, the office building of Tokyo Branch Office of East Japan Railway Company accomplished $33 \%$ reduction in electric energy consumption compared with that in 2010, before the huge earthquake in 2011 and nuclear crisis after that, as shown in Fig. 3 [4]. Regarding renewable energy utilization, there are a lot of examples of rooftop photovoltaic system installations at railway stations in Japan [5]. Among these solutions to improve energy efficiency in railway system, 


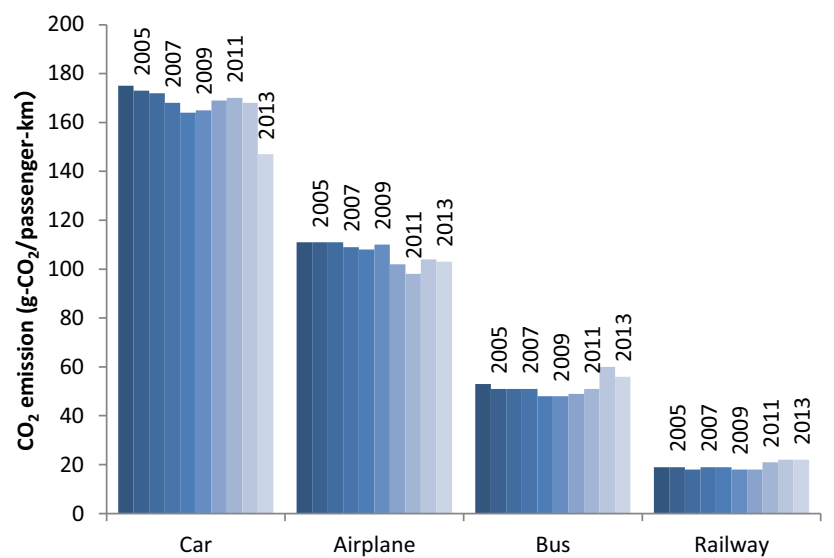

Fig. $1 \mathrm{CO}_{2}$ emissions per passenger per kilometer

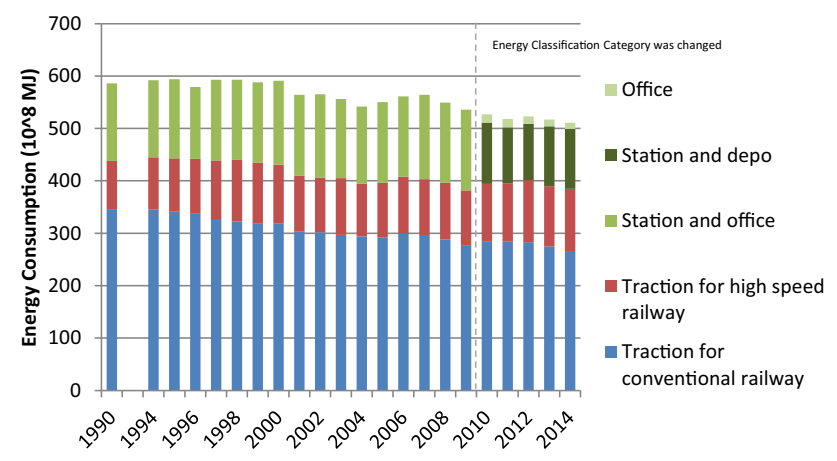

Fig. 2 Change in energy consumption in East Japan Railway Company (JR East)

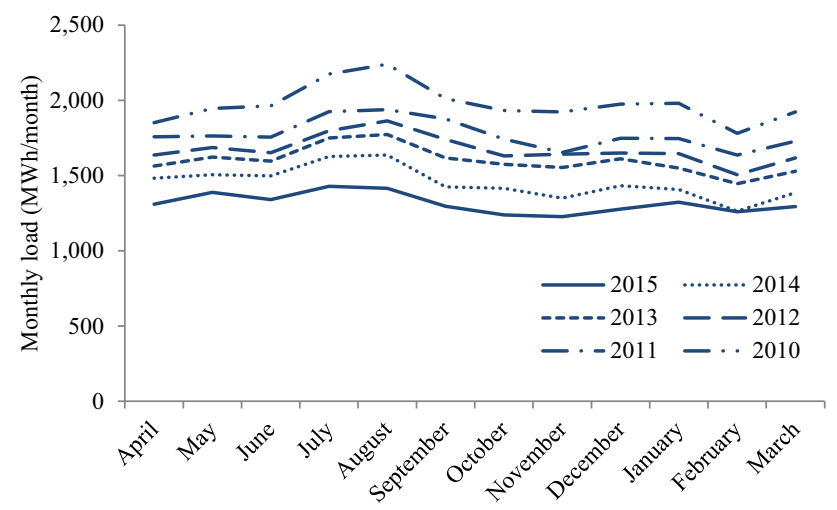

Fig. 3 Changes in electric energy consumption at Tokyo Branch Office building of JR East

the enhancement of regenerative energy utilization is one of the most actively discussed technical issues, and the recent Japanese trends in this topic will be summarized in this article.

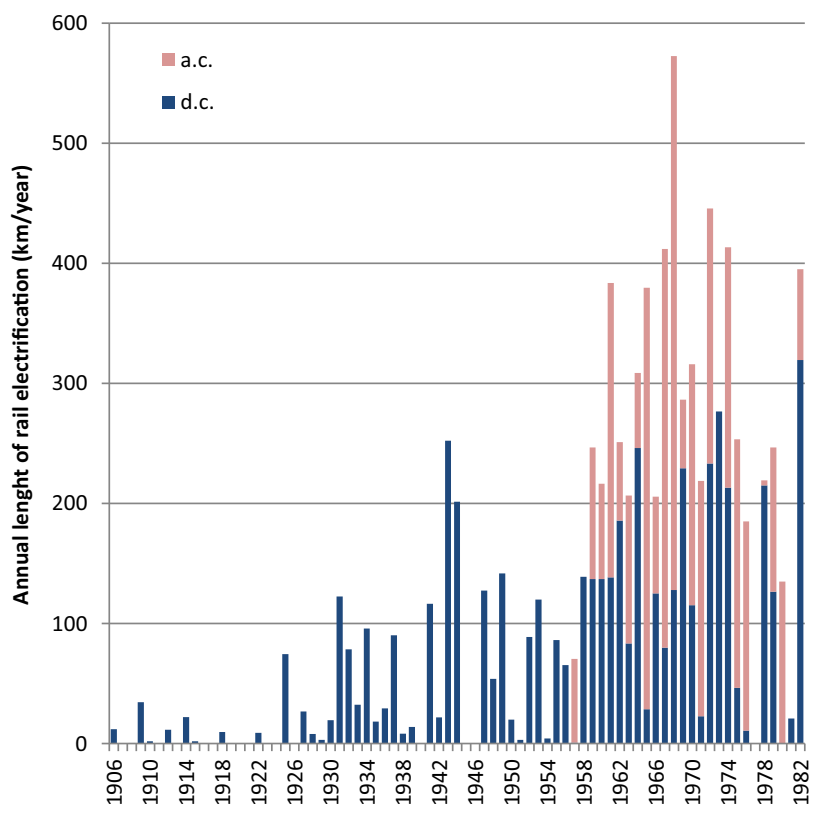

Fig. 4 Annual length of rail electrification in Japan National Railway

\section{Development of Electric Railway in Japan}

Figure 4 shows the history of rail electrification in former Japan National Railway. The first demonstration of electric railway was performed by Dr. Ichisuke Fujioka at the third domestic industrial exposition at Ueno in Tokyo in 1890. Five years later, the first electric tram started business operation in Kyoto and the first electrification of full-scale railway was realized in Tokyo in 1904 which was merged with Japan National Railway in 1906. As shown in this figure, rail electrification was strongly promoted during the period of rapid economic growth around 1960s. As a result, the electric railway network all over Japan was formed as shown in Fig. 5. In this figure, only the mass rail transit lines operated by JR group, former Japan National Railway, are described.

\section{Regenerative Energy Utilization}

In DC traction power supply system around large cities, regenerative energy utilization is actively discussed during the last decade to improve the energy efficiency of DC electric railway in Japan. To make use of the residual regenerative power efficiently, there have been some solutions conventionally. Figure 6 summarizes conventional possible solutions mainly for avoiding the cancelation of regeneration which have already been realized in Japan $[6,7]$.

As shown in Fig. 6a, regenerative resistance is one of the most effective solutions but the residual power is not 
utilized in this solution. Tie feeding shown in Fig. $6 \mathrm{~b}$ is a low-cost solution, and it was reported that it contributed to realize about $2 \%$ of energy saving by some railway companies. If there are enough electric loads on the $6 \mathrm{kV}$ distribution lines to feed residual regenerative power to stations and signaling systems along the railroad trackside, regenerative inverter shown in Fig. $6 \mathrm{c}$ will be able to become one of the most effective solutions for regenerative power utilization. In a DC traction power supply system for subway, it is the most feasible countermeasure against regenerative brake cancelation because the load of railway station for subway is large enough for simultaneous

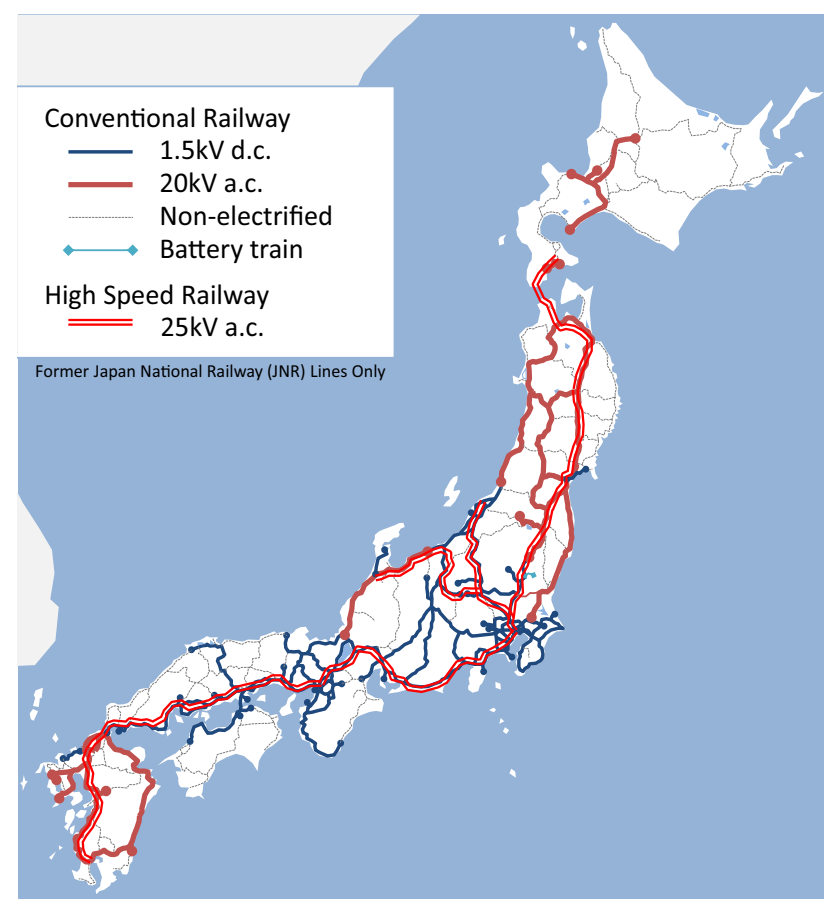

Fig. 5 Electrification of Japanese railway network utilization of residual regenerative power. PWM converter shown in Fig. 6d is almost the same as regenerative inverter, but the regenerative power is reversed from DC power system for railway to the utility grid directly.

Compared with these existing solutions, the installation of energy storage system can be effective and is independent to other electric loads and operation schedules of trains. Furthermore, it is getting feasible more and more because of the cost reduction of energy storage system, such as lithium-ion battery, in Japan. Figure 7 shows the simplified concept of the function of energy storage system installation into DC traction power supply system. As shown in Fig. 7a, if there is another powering train adjacent to the braking train with regenerative brakes, the regenerative energy from braking train is consumed by the other powering train simultaneously. Because of the voltage drop of the catenaries system, on the other hand, it is impossible to transfer the regenerative energy for a long distance, and the regenerative energy is canceled if there is no powering train near the braking train as shown in Fig. 7b. To avoid such a regenerative brake cancelation, the energy storage system is installed along the railroad trackside and the residual regenerative power is charged to energy storage system during the braking period and will be utilized for the powering later.

Figure 8 shows the existing energy storage systems in traction power supply system, $1.5 \mathrm{kV}$ or $750 \mathrm{~V}$, in Japan. As shown in this figure, Li-ion battery is most popular for the energy storage system in traction power supply system because of its cost-effectiveness. As other storage mediums, nickel-metal hydride batteries and electric doublelayer capacitors, called "Super-capacitor" in China and Europe, are selected in some railway companies. Generally, the required capacity to charge all regenerative energy for one braking opportunity is more than $10 \mathrm{kWh}$ in

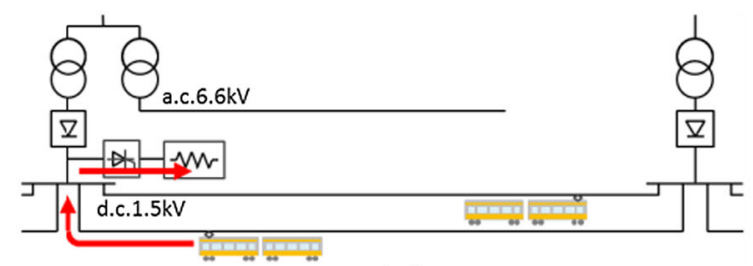

(a)

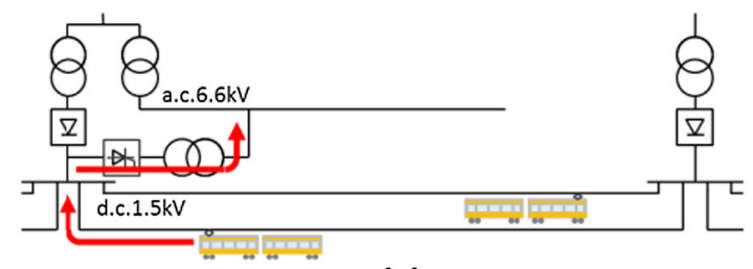

(c)

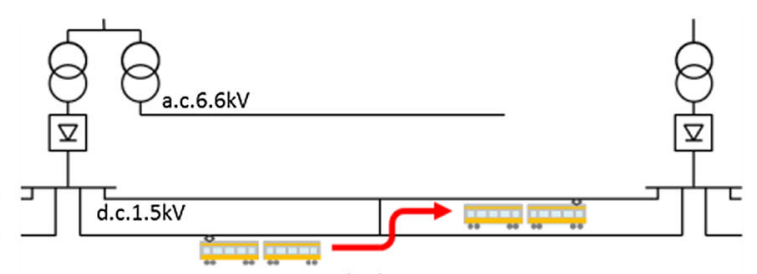

(b)

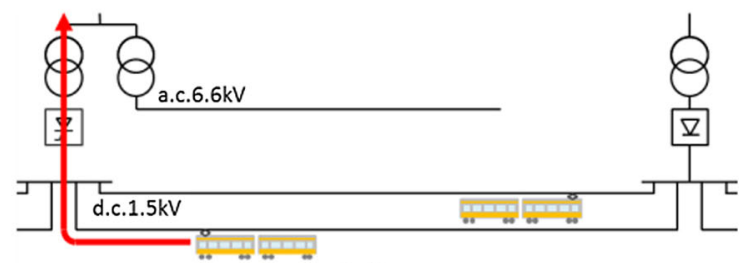

(d)

Fig. 6 Conventional solutions against residual regenerative energy. a Regenerative resistance, $\mathbf{b}$ tie feeding, $\mathbf{c}$ regenerative inverter, $\mathbf{d}$ PWM converter 
Fig. 7 Concept of energy storage system in DC traction power supply system. a Braking with powering train, b braking without powering train, c braking without powering train, but with energy storage system

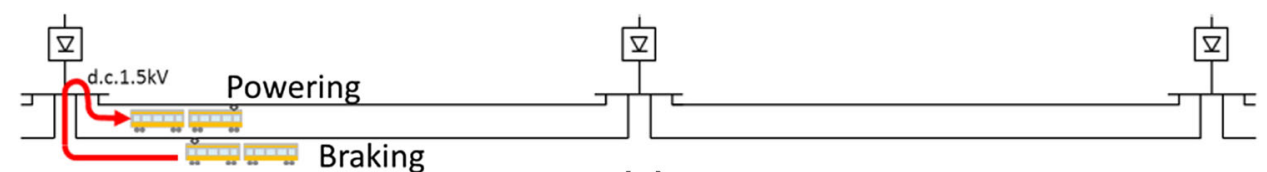

(a)

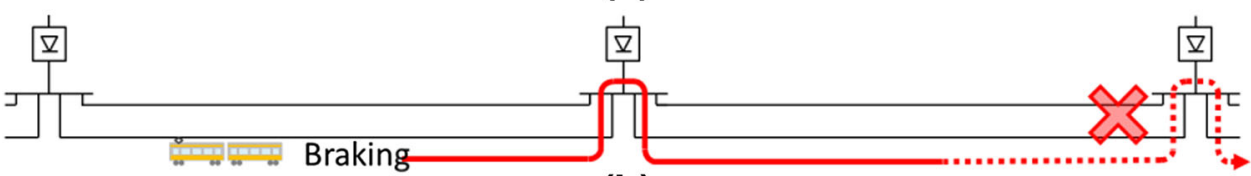

(b)

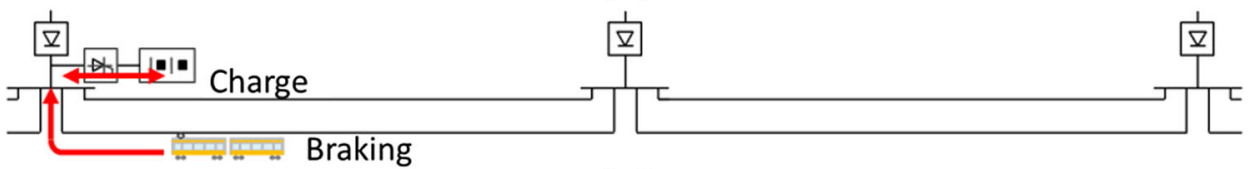

(c)

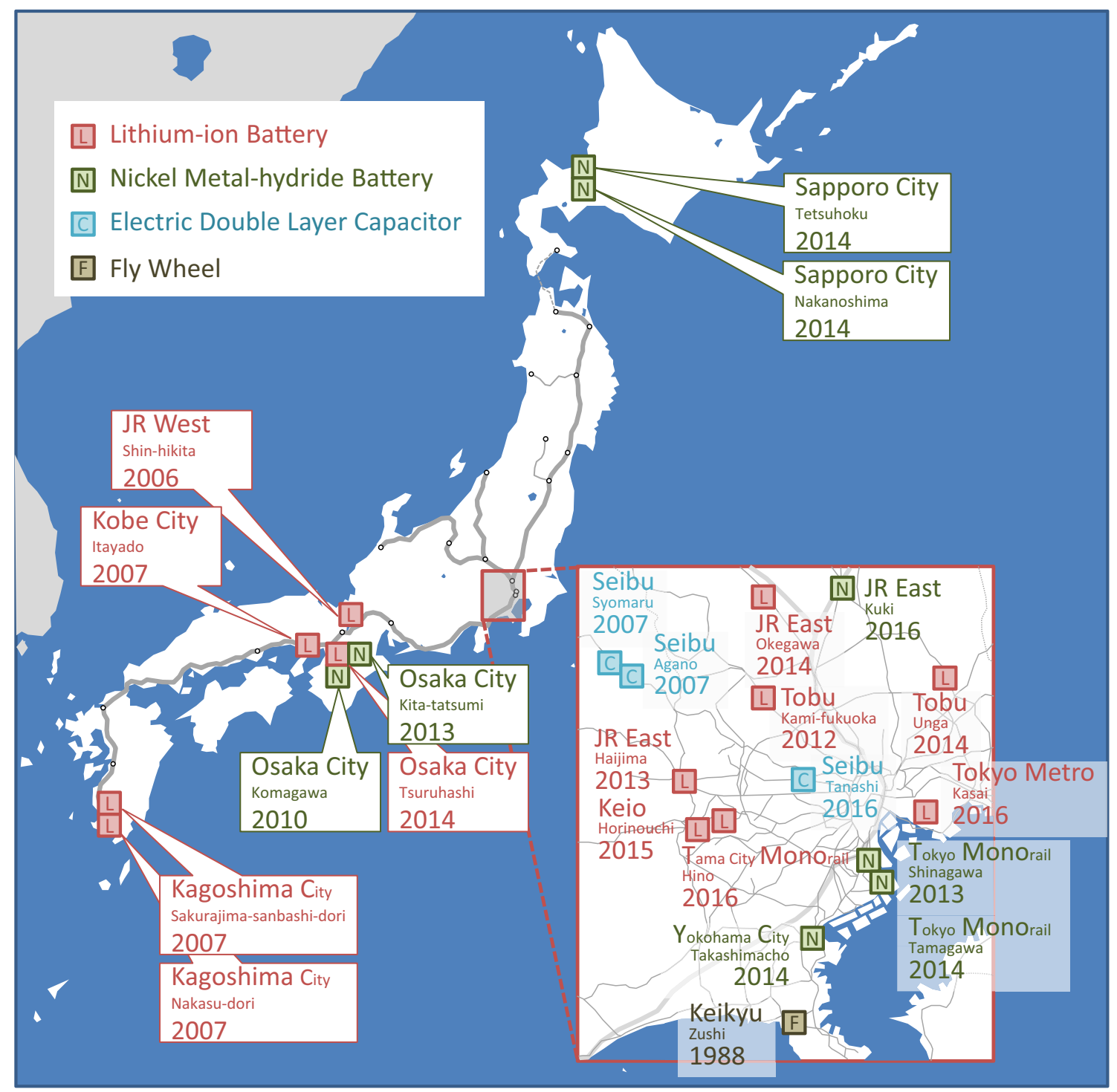

Fig. 8 Existing energy storage systems in DC traction power supply system in Japan 
Japanese commuting trains with more than 10 cars, and the battery system is more appropriate to realize such a large capacity than a capacitor system. As a special case, fly wheel system was installed more than 25 years ago on Keihin Express Line for voltage drop compensation at the end of the DC traction power supply system. As shown in Fig. 8, more than 20 energy storage systems have already been installed in DC traction power supply system in Japan since 2006. The main purpose of installation of energy storage system is as follows:

- Compensation for voltage drop

- Avoidance of regenerative braking cancelation

- Utilization of regenerative energy

- Emergency power supply

Figure 9 shows the change in the number of traction substations where energy storage systems were newly installed. The installation of energy storage system is strongly promoted recently not only because of the support in relation to the subsidy from government, but also because of the cost reduction of energy storage system. Such a trend has been strongly supported by the governmental promotion to utilize renewable energy after the huge earthquake of 2011 in the eastern part of Japan and nuclear crisis immediately after the earthquake.

\section{Experiences in East Japan Railway Company}

\subsection{Regenerative Energy Utilization in DC Traction Power Supply System}

We, East Japan Railway Company, have already installed three energy storage systems for the utilization of regenerative energy around the metropolitan area of Tokyo as shown in Fig. 10. They were installed at Haijima SS, Okegawa SS and Kuki SS, respectively. These substations are located about $40 \mathrm{~km}$ away from Tokyo central station,

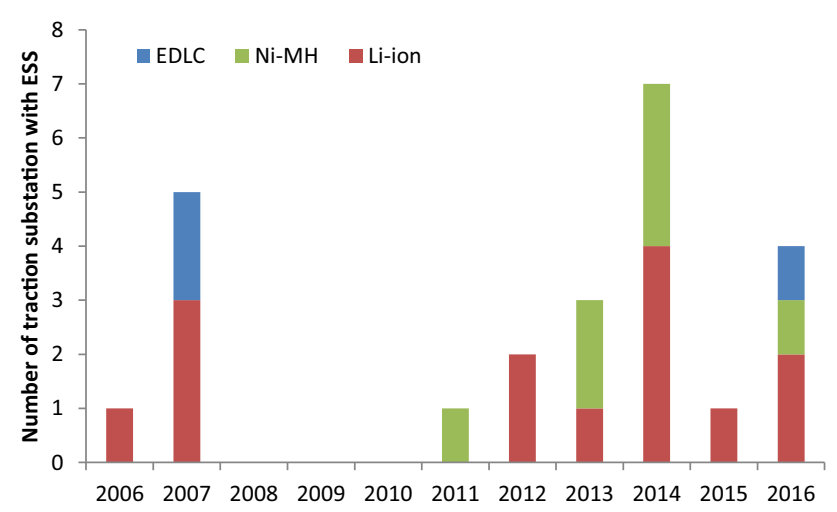

Fig. 9 Change in the number of traction substation where ESS is newly installed and the installed mediums

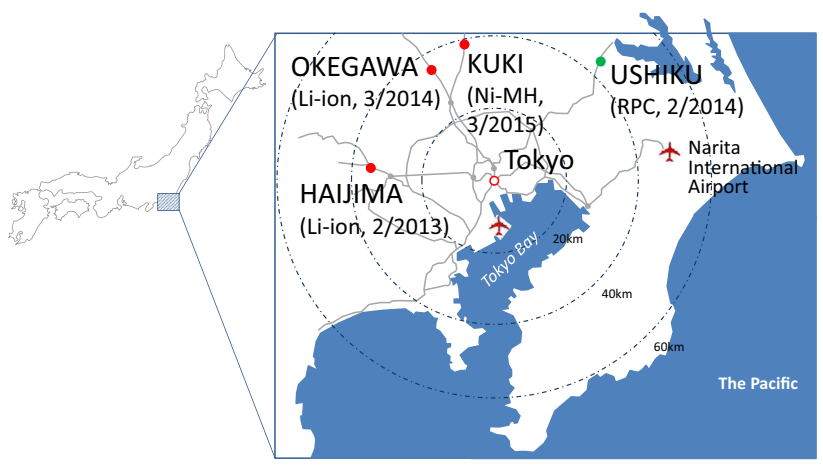

Fig. 10 Location of three energy storage systems in East Japan Railway Company

and according to our previous experience, such a suburban area is appropriate for energy storage system installation for the utilization of regenerative energy. In the central part of the metropolitan area of Tokyo where the time interval between train operations is less than $5 \mathrm{~min}$, the operation frequency of railway is so high that all regenerative energy is utilized by the other powering trains simultaneously and it is not necessary to install energy storage system. On the other hand, in the countryside where the time interval between train operations is more than $10 \mathrm{~min}$, the total amount of residual regenerative energy is not enough for the investment of energy storage system installation. Based on the detail measurements of consumed and residual regenerative power around the Osaka area which was carried out by West Japan Railway Company 5 years ago, they concluded that $7 \mathrm{~min}$ interval length of train operation was the most appropriate for energy storage system installation [8]. It is important to choose appropriate location in order for installations of energy storage system to be cost effective.

Table 1 shows the specifications of energy storage systems at Haijima SS and Okegawa SS. The energy-saving effects based on the first one-year operation are also shown in this table. Figure 11 shows the comparison of the daily energy supply from Okegawa SS before and after the installation of energy storage system in March 2014, and the ratio of discharged energy from battery to total energy supply from Okegawa SS is shown in Fig. 12. As shown in these figures, the installation of energy storage system contributes to the reduction of supply energy from traction substation of about $10 \%$ and it becomes maximum values during the middle seasons, in spring and in autumn. In summer and in winter, onboard air-conditioning loads are large and some part of the residual regenerative energy is utilized on board. The amount of residual regenerative energy becomes small in these seasons compared with the middle seasons.

As shown in Table 1, annual energy-saving effect is about $700 \mathrm{MWh} /$ year at Okegawa SS and the payback year 
Table 1 Specifications of energy storage system installed at Haijima SS and Okegawa SS

\begin{tabular}{lll}
\hline & Haijima SS & Okegawa SS \\
\hline System & & \\
Rated capacity & $2000 \mathrm{~kW}$ & \\
Rated voltage & $1650 \mathrm{~V}$ \\
Rated current & $1210 \mathrm{~A}$ & \\
Battery & & \\
Devices & Lithium-ion & \\
Module capacity & $173 \mathrm{~V}, 5.5 \mathrm{Ah}$ & 4 series, 36 parallel \\
Configuration & 4 series, 20 parallel & $3000 \mathrm{~A}$ \\
Maximum current & $3000 \mathrm{~A}$ & $137.02 \mathrm{kWh}$ \\
Rated capacity & $76.12 \mathrm{kWh}$ & \\
DC/DC converter & & \\
Devices & IGBT & \\
Parallel number & 6 & March, 2014 \\
Carrier frequency & $600 \mathrm{~Hz}$ & $700 \mathrm{MWh} / \mathrm{year}$ \\
Operation start & February, 2013 & \\
Energy-saving effect of 1st 1 year & $400 \mathrm{MW} / \mathrm{year}$ & \\
Manufacturer & Hitachi Co., Ltd. & \\
\hline
\end{tabular}

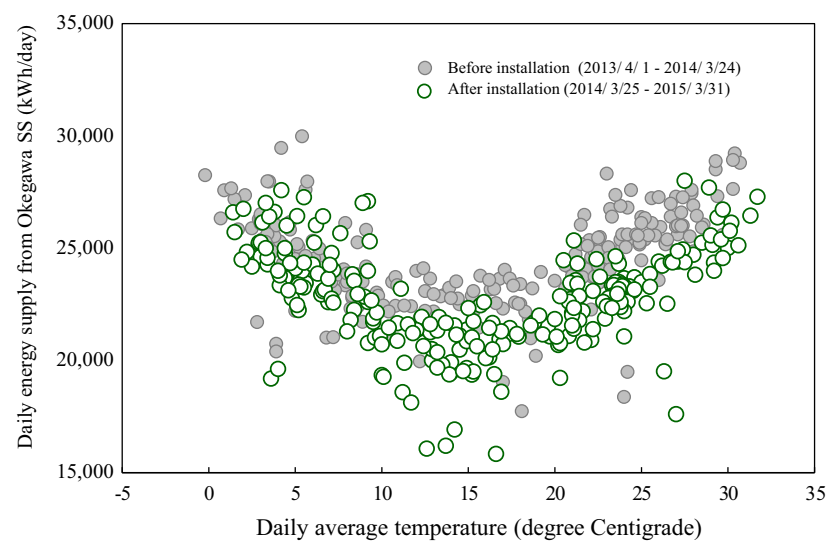

Fig. 11 Effect of energy storage system at Okegawa SS

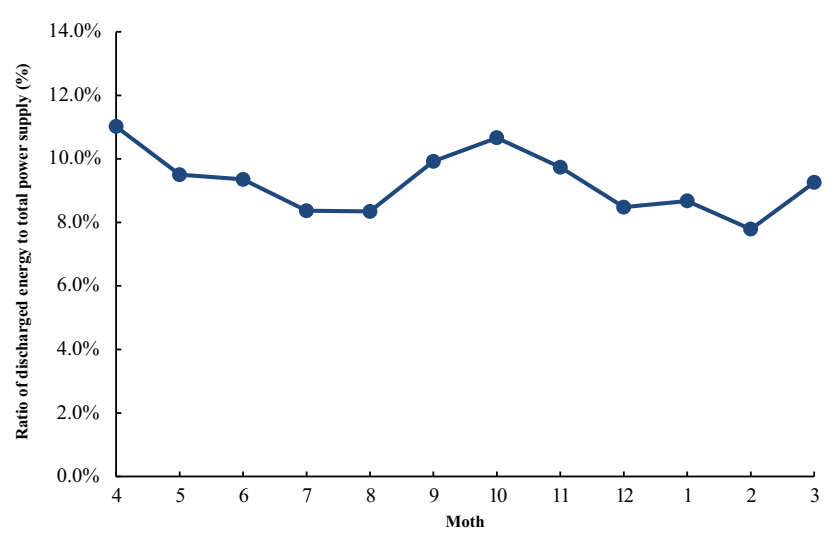

Fig. 12 Ratio of discharged energy to total energy supply from SS for investment is about 30 years considering maintenance cost and battery replacement cost. Here, it is supposed that the lifetime of battery will be 15 years because only $25 \%$ of battery capacity is used for daily operation now to make battery lifetime longer. In the normal operation, state of charge (SOC) of the battery is controlled to be from $30 \%$ to $50 \%$ and such a narrow range operation is expected to make the lifetime of the battery system last about 15 years.

\subsection{Regenerative Energy Utilization in AC Traction Power Supply System}

Generally speaking, AC traction power supply system is applied for rural areas in Japan as shown in Fig. 5, and the total amount of residual regenerative energy tends to be small in AC traction power supply system because of its low operation frequency. The Joban Line was, exceptionally, electrified by AC $20 \mathrm{kV}$ near Tokyo area because there is Kakioka Magnetic Observatory of Japan Meteorological Agency and so the DC electrification of railway was restricted by the low frequency of operations to avoid the influence of DC stray current on the survey of geomagnetic intensity. In this area, the number of operated electric trains is moderate enough because Ushiku SP (Sectioning Post) on Joban Line is located near Tokyo, about $40 \mathrm{~km}$ from city center. Here, SP is located between two substations and two single-phase circuits from each substation are faced at SP.

RPC, railway static power conditioner, was originally developed to solve the unbalanced three-phase voltage problem at the receiving point of traction substation for high-speed railway caused by single-phase train loads. Two 
RPCs were installed at Shin-Numakunai SS and ShinHachinohe SS on Tohoku Shinkansen Line in 2002. Because RPC can realize power interchange between two different electric circuits with phase difference via $\mathrm{AC} / \mathrm{DC} /$ $\mathrm{AC}$ conversion, it can increase the opportunity of simultaneous utilization of residual regenerative power by interchanging the residuals to adjacent electric circuit. Figure 13 shows the circuit configuration around RPC at Ushiku SP [10]. Ushiku SP is located between Fujishiro SS and Tsuchiura SS on Joban Line, and RPC can interchange residual regenerative power from one feeder circuit to another. Conventionally, residual regenerative energy is reversed from traction power supply system to the grid via traction transformers at substations, and it is not reflected to the electric charge for railway operation. Furthermore, there is no confirmation that such a back-flown singlephase power is utilized appropriately in the grid. Installation of RPC at SP can realize certain utilization of regenerative energy within traction power supply system. Figure 14 shows the concept of regenerative power flow without and with RPC at SP.

The change in interchanged energy per day from April to November in 2015 is shown in Fig. 15. Here, the interchanged power is controlled by referring the power supply from adjacent traction substations, Fujishiro SS and Tsuchiura SS. Hence, the interchanged power is always utilized in the adjacent circuit and it is possible to recognize the amount of interchanged energy as the effect of RPC. It is confirmed that the converted regenerative power is not backflown from the railway power supply system to the grid via traction transformer at another traction substation. The effect of RPC depends on the seasons as shown in Fig. 15, similar to the tendency of energy storage system mentioned in the previous section. The annual effect of RPC at Ushiku SP was estimated to be about $2500 \mathrm{MWh} /$ year or more according to the first 8-month operation results. This effect is estimated according to the interchanged energy through RPC. If it is possible to estimate the effect according to the history of total supplied energy, it will be easier for gaining understanding. However, it is difficult to distinguish the effect of RPC from other factors, such as weather, operation diagrams and types of rolling stocks, and such an estimation from interchanged energy is applied here.

\subsection{Future Prospects}

Now, the designing of one energy storage system is underway to be installed at Kita-Senju SS on Joban Line

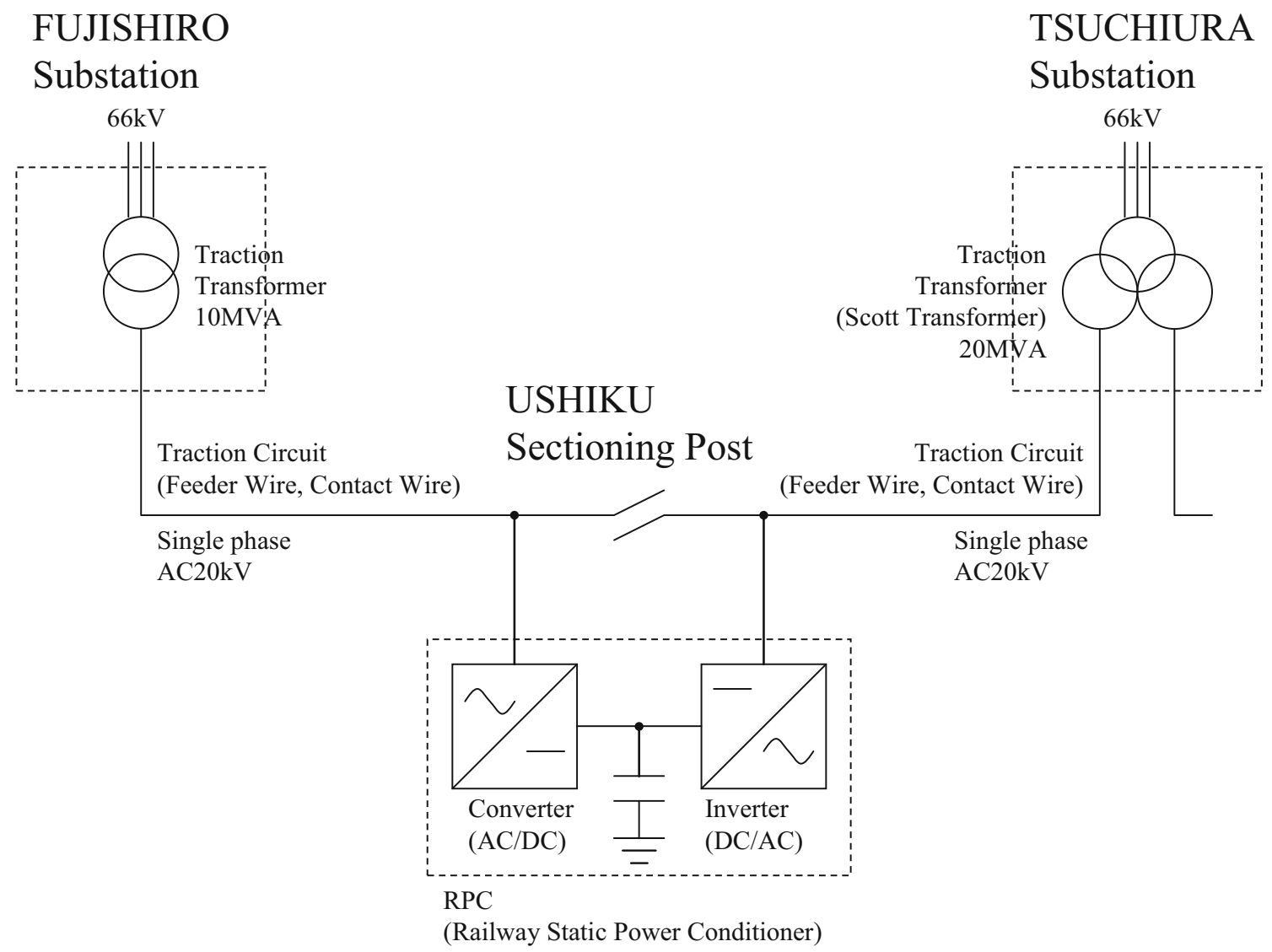

Fig. 13 Circuit configuration around RPC at Ushiku SP 


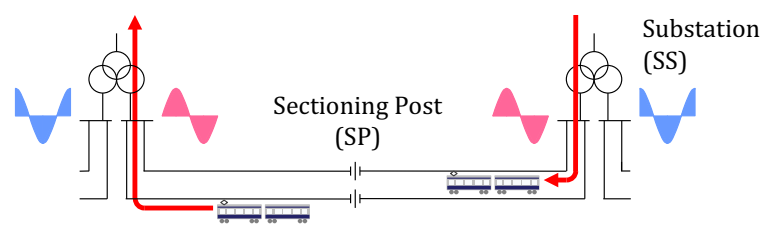

(a)

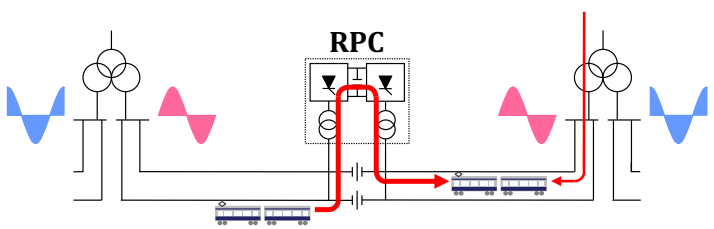

(b)

Fig. 14 Regenerative power flow without and with RPC at SP. a Without RPC, b with RPC

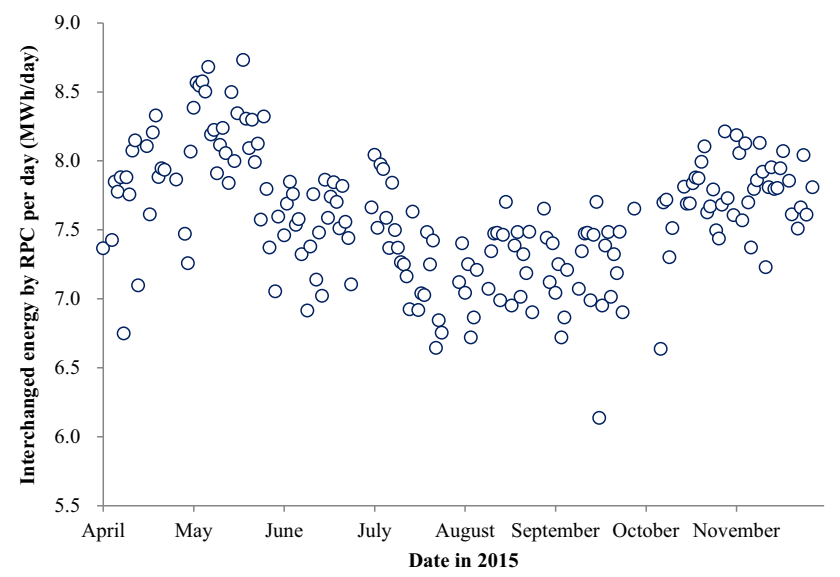

Fig. 15 Daily effect of RPC at Ushiku SP during the first 8 months operation

near Tokyo. This will be the fourth energy storage system installed by East Japan Railway Company. As a storage medium, lithium-ion battery will be applied in this system. In these days, the total cost of energy storage system installation is about 200 million Japanese Yen including the construction cost and the payback year will be around 30 years. Due to the fact that the substations where large effect of energy storage system is expected have already been selected for the previous installation, additional cost reduction is required for more installations of energy storage systems around Tokyo in the future.

Two regenerative inverters are under construction in JR East at Kajibashi SS at Tokyo Statin and Fukiage SS on Takasaki Line. Since the station load is smaller than the regenerative power at average stations, we did not choose regenerative inverter as a solution for regenerative energy utilization previously. Regenerative inverter is generally a solution for subway system whose station load is large enough. At Kajibashi SS, however, there is a huge load of Tokyo Station and the regenerative inverter is selected as a solution for regenerative energy utilization for the first time in JR East. At Fukiage SS, there is a dedicated high-voltage transmission line to connect several traction substations on Takasaki Line, and the converted regenerative power can be consumed only for the railway system along the line simultaneously.
Regarding regenerative energy utilization in high-speed railway, there is a large potential but the installation costs is not feasible under the actual conditions [9].

\section{Conclusions}

In this paper, the recent trend of regenerative energy utilization in traction power supply system in Japan is summarized. As a conclusion, I would like to mention some topics which should be discussed and considered more in the future.

Firstly, evaluation methods of the effects of the energy storage system and regenerative inverter should be established and standardized. The installation of such solutions can improve the level of energy efficiency at the installed substation but it can deteriorate those at adjacent substations in some cases. Also, power supply is influenced by weather, operation diagram, train characteristics, and so on. The effect of solutions has to be distinguished from the influences by other factors. Proposal of international standard to evaluate the effects of energy storage system or regenerative inverter system should be required in the future.

Secondly, the control scheme of charge and discharge of battery system and the design scheme on deciding the capacity of converter and energy storage system should be established. We are now making efforts by repeating trials and errors. The designing methods of energy storage system for regenerative energy utilization will be gradually matured in the future.

Lastly, but not least, optimal system design between onground and onboard energy storage system will be required in the future. Nowadays, energy storage system tends to be installed on ground because of its volume and weight problems. In the future, if the energy density of the storage medium is improved and the rapid charging technology is developed, the optimal solution will be changed. A comprehensive design scheme for regenerative energy utilization will be required in the future.

In November 2016, I was invited to the Chinese symposium of regenerative energy utilization in railway system at Zhenjiang held by Beijing Jiaotong University. I came to 
know that there are a lot of discussions in China about almost the same issues related to the regenerative energy utilization as in Japan. As you know, subway systems have already been constructed in 25 cities in China, and thus has a lot of experiences not only in AC high-speed railway [11] but also in DC urban railway [12]. I hope our collaborations between China and Japan in this technical field will be promoted more in the future and result in the realization of a more efficient, reasonable and advanced traction power supply system, and we are able to continue to contribute to the sustainable development of our future society together.

Open Access This article is distributed under the terms of the Creative Commons Attribution 4.0 International License (http://crea tivecommons.org/licenses/by/4.0/), which permits unrestricted use, distribution, and reproduction in any medium, provided you give appropriate credit to the original author(s) and the source, provide a link to the Creative Commons license, and indicate if changes were made.

\section{References}

1. Web page of the Ministry of Land, Infrastructure, Transport and Tourism, Japan. http://www.mlit.go.jp/common/001117515.pdf (in Japanese)

2. Web page of the Ministry of Land, Infrastructure, Transport and Tourism, Japan. http://www.mlit.go.jp/tetudo/tetudo_tk2 000027.html (in Japanese)

3. Web page of the Ministry of Foreign Affairs, Japan. http://www. mofa.go.jp/mofaj/files/000090898.pdf

4. Hayashiya H (2016) Energy consumption in railway company. In: 2016 IEE-Japan industry application society conference, No.5S1-1 (in Japanese)
5. Hayashiya H, Furukawa T, Itagaki H, Kuraoka T, Morita Y, Fukasawa Y, Mitoma Y, Oikawa T (2012) Potentials, peculiarities and prospects of solar power generation on the railway premises. In: 1st international conference on renewable energy research and applications (ICRERA2012)

6. Hayashiya H, Suzuki T, Kawahara K, Yamanoi T (2014) Comparative study of investment and efficiency to reduce energy consumption in traction power supply. In: 16th international conference on power electronics and motion control (PEMC2014), No.229

7. Hayashiya H, Suzuki T, Hino M, Hara D, Tojo M, Shimada S, Kudo K (2015) Effect evaluation of Li-ion battery for regenerative energy utilization in traction power supply system. In: 17th European conference on power electronics and applications (EPE2015), No.0035

8. Hayashiya H, Suzuki T, Kawahara K, Yamanoi T (2014) Comparative study of investment and efficiency to reduce energy consumption in traction power supply. In: 16th international conference on power electronics and motion control (PEMC2014), No.229

9. Hayashiya H, Yokokawa S, Iino Y, Kikuchi S, Suzuki T, Uematsu S, Sato N, Usui T (2016) Regenerative energy utilization in a.c. traction power supply system. In: Proceedings of the 2016 IEEE international power electronics and motion control conference (PEMC)

10. Hayashiya H, Kikuchi S, Matsuura K, Hino M, Tojo M, Kato T, Ando M, Oikawa T, Kamata M, Munakata H (2013) Possibility of energy saving by introducing energy conversion and energy storage technologies in traction power supply system. In: 15th European conference on power electronics and applications (EPE2013)

11. Li Q, Liu W, Shu Z, Xie S, Zhou F (2014) Co-phase power supply system for HSR. In: International power electronics conference (IPEC-Horoshima 2014-ECCE Asia), No.19J1-2

12. Yang Z, Xia H, Wang B, Lin F (2014) An overview on braking energy regeneration technologies in Chinese urban railway transportation. In: International power electronics conference (IPEC-Horoshima 2014-ECCE Asia), No.20G4-4 